\title{
3 Research Square

\section{Effective microRNAs in Ischemia/Reperfusion Before and After Bypass Graft Surgery in Coronary Artery Patients}

\section{Erman Kandilli}

Gaziantep Universitesi Tip Fakultesi

Şenay Görücü Yılmaz ( $\sim$ gorucu@gantep.edu.tr)

Gaziantep Universitesi https://orcid.org/0000-0003-0523-7819

\section{Murat Yardımcı}

Sanko Universitesi Tip Fakultesi

\section{Necla Benlier}

Sanko Universitesi Tip Fakultesi

\section{Muradiye Nacak}

Gaziantep Universitesi Tip Fakultesi

\section{Research}

Keywords: microRNA, coronary artery disease, by-pass graft surgery, epigenetics, ischemia/reperfusion

Posted Date: July 24th, 2020

DOI: https://doi.org/10.21203/rs.3.rs-42361/v1

License: (c) (1) This work is licensed under a Creative Commons Attribution 4.0 International License. Read Full License 


\section{Abstract}

\section{Background}

Cardiovascular diseases (CVD) are among the causes of morbidity and mortality in the world. Significant advances have been made in the diagnosis, treatment and prognosis of CVD. New biomarkers and therapeutic targets are needed to reduce the incidence of this disease. Recently, there is growing evidence that circulating microRNAs can be used as diagnostic biomarkers in this disease.

\section{Methods}

We compared five microRNA (hsa-miR-21-5p, hsa-mi181a-5p, hsa-miR-199a-5p, hsa-miR-199b-5p and hsa-miR-320a) expression levels associated with ischemia/reperfusion before and after bypass graft surgery in serum samples of patients $(\mathrm{N}=46)$ with coronary artery disease and healthy control subjects $(\mathrm{N}=48)$. Expression measurements were made for each miRNA preoperatively and postoperatively at 1 . and 24. hours, and then compared with the control subjects. Troponin I, creatine phosphate kinase and creatine kinase myocardial band cardiac markers were measured before and 1 and 24 hours postoperatively and compared to miRNA expressions and controls. Quantitative real-time PCR was used for expression analysis. The data were analyzed by Mann-Whitney test, chi-squared test, Logistic Regression analysis, and Kruskal-Wallis test with the statistical package SPSS.

\section{Results}

The five miRNAs were down-regulated compared to controls. The expression level for miR-199a at $24 \mathrm{~h}$ postoperatively was significantly lower than at $1 \mathrm{~h}(\mathrm{p}=0.001)$. Receiver operating characteristic analysis showed that the area under the curve of miR-199a-5p was 0.810 (sensitivity $87 \%$ and specificity $68.5 \%$ ) in preoperative patients.

\section{Conclusions:}

miR-199a and miR-199b in serum are a novel non-invasive biomarker candidate for coronary artery disease.

\section{Background}

Currently, cardiovascular disease (CVD) is the most important cause of mortality in the middle and old age group and constitutes $31 \%$ of global deaths. It is estimated that CVD causes approximately 17.7 million deaths each year in the world [1]. The number of people dying from CVD is estimated to be more than 24 million by 2030 [2]. According to data TEKHARF (Prevalence of Heart Disease and Risk Factors in Turkish Adults) of 2017, 43\% of deaths in Turkey is caused by coronary heart disease. There are approximately 3.5 million coronary heart patients in our country. It is estimated that this number increases by $4 \%$ annually and 210 thousand people die annually from coronary heart disease [3]. 
Ischemic damage due to coronary heart disease leads to permanent damage to the cardiac tissue, and a decrease in contractility set the stage for heart failure. In heart failure, hypertrophy of myocytes at cellular level, inflammation, mitochondrial dysfunction, cardiac fibrosis, arrhythmia, vascular defects, endothelial cell viability and decreased cardiomyocytes are observed. Factors that influence these results at the molecular level include a variety of gene regulatory networks, including transcription factors, coactivators, repressors, promoter DNA regions, promoter elements, and chromatin exchange enzymes [4].

MicroRNAs (miRNAs) are a small class of non-encoded RNAs of 20-25 nucleotides in length that act as a molecular switch for gene expression. They are involved in many important cellular processes such as proliferation, differentiation, cell metabolism, apoptosis and angiogenesis. They regulate gene expression by inhibiting protein translation from mRNA or by degrading mRNA at the post-transcriptional level $[4,5]$.

To date, the studies examining the association between miRNAs and vascular disease have shown that there are few studies evaluating miRNAs in patients with coronary artery bypass grafts. Therefore, we have selected five miRNAs (miR-21, miR-199a, miR-199b, miR181a and miR320a) that may be associated with ischemia/reperfusion (I/R) in coronary artery disease patients that are not adequately investigated. We aimed to compare the levels of these miRNAs both in the healthy control group and before the surgical treatment in which the coronary vessels could not provide sufficient oxygen in the patients who would undergo bypass graft surgery due to coronary artery disease and after the surgical treatment in which reperfusion was provided. Another aim was to determine whether there is a correlation between miRNA levels and cardiac markers (cardiac troponin I and creatinine kinase MB). Thus, we think that miRNAs may change due to reperfusion of the heart and we can obtain concrete data about these changes. We hope that these data will be evaluated as biomarkers in patients with coronary artery disease in the coming years and will provide us with predictions about the prognosis of coronary artery disease.

\section{Materials And Methods}

\section{Selection of volunteers}

The study was conducted on 46 patients and 48 healthy volunteers who applied to Cardiovascular Surgery Department of Sanko University Research and Application Hospital in Turkey. The patient group consisted of volunteers aged between 18-65 years with a history of coronary artery disease, myocardial infarction, coronary artery stenosis greater than $70 \%$, left ventricular ejection fraction between $30 \%$ and $55 \%$ and without diabetes mellitus, malignant diseases and chronic renal failure. The control group consisted of healthy volunteers between 18-65 years of age, without coronary artery disease and discomfort that could affect related miRNAs. Peripheral blood samples were obtained from 46 patients who accepted to undergo coronary artery bypass surgery preoperatively. Peripheral blood samples were collected preoperatively and at the 1st and 24th hours after the operation. Blood samples of healthy individuals were collected from the same clinic and who had no disease that could affect coronary artery disease and related miRNAs. Informed consent was obtained from each patient and the study protocol 
conforms to the ethical guidelines of the 2013 Declaration of Helsinki as reflected in a priori approval by the institution's human research committee. This study was approved by Gaziantep University Medical School Medical Ethics Committee.

\section{Plasma Sampling}

$5 \mathrm{ml}$ blood samples from each individual were taken into tubes containing 7.5\% EDTA. The tubes were centrifuged at $2000 \mathrm{rpm}$ for $15 \mathrm{~min}$. Then, the approximately 1000 microliter plasma was centrifuged again at $2000 \mathrm{rpm}$ for 5 minutes and placed into a $200 \mu \mathrm{L}$ clean micro centrifuge tube without touching the supernatant from the top. Micro centrifuge tubes were labeled with the patient's barcode label. A total of 192 plasma samples were stored at $-80^{\circ} \mathrm{C}$ until RNA isolation. Also, biochemical parameters (LDH, BUN, Glucose, Troponin I, CK, and CK-MB) of the blood samples of the patient and control groups were measured in the Biochemistry Laboratory (Sanko University Research and Application Hospital in Turkey). Plasma samples were coded as pre-op, 1-hour post-op (OP1), 24-hours post-op (OP24) and control group $(\mathrm{K})$.

\section{RNA Extraction}

Total RNAs containing microRNAs were obtained from plasma using the miRNeasy RNA Isolation Kit (Qiagen, Hilden, Germany). cel-miR-39 was used as spike-in control. RNA was obtained according to the manufacturer's instructions and then stored at $-80^{\circ} \mathrm{C}$ for further studies.

\section{Complementary DNA (CDNA) reaction preparation}

Isolated RNAs were transformed into cDNA using the Qiagen miScript II kit. 50 microliters of reaction mix were prepared as $5 \mathrm{x}$ miScript Hispec buffer, 10x miScript Nucleics mix, DNase-RNase free water and $2 \mathrm{ng}$ RNA. Samples were amplified by holding at $37^{\circ} \mathrm{C}$ for $60 \mathrm{~min}$. and at $95^{\circ} \mathrm{C}$ for $5 \mathrm{~min}$. The obtained cDNA samples were diluted with nuclease-free water in $1 / 5$ ratio and stored at $-20^{\circ} \mathrm{C}$ until expression.

\section{Reverse Transcription Reactions}

Total RNA samples (3.5 ml) were converted to cDNA using the Qiagen miScript II Kit (Cat.No:218161). At this stage, $5 x$ miScript Hispec buffer, 10x miScript Nucleics mix, DNase-RNase free water and miScript Rev. A transcriptase mix was added to the total RNA and the total reaction volume was completed to 7 $\mathrm{ml}$. Samples were placed in the thermal cycler (Bioer GenePro Thermal Cycler) and the reverse transcription reaction was performed at $37^{\circ} \mathrm{C}$ for $60 \mathrm{~min} .95^{\circ} \mathrm{C}$ for $5 \mathrm{~min} .4$ Set to ${ }^{\circ} \mathrm{C} ¥$. Then, $\mathrm{CDNA}$ samples were diluted 1/5 with nuclease-free water. The Qiagen miScript Microfluidics PreAMP kit and the Qiagen miScript Primary Assay [cel-miR-39 (MS00080247), miRTC (218161), miR-21-5p (MS00009079), miR-199a-5p (MS00006741), miR-199b-5p (MS00006741), miR-181a-5p (MS00008827), miR-320a (MS00014707)] were used for the pre-amplification reaction. MiRTC is a miRNA reverse transcription control and was used to evaluate reverse transcription performance. Another control is cel-miR-39 and 
exogenously spiked cel-miR-39 was used for alternative data normalization. The pre-amplification mix were added to diluted cDNA samples. Samples were placed in thermal cycler (Bioer GenePro Thermal Cycler). Thermal program for pre-amplification reaction $15 \min$ for $95^{\circ} \mathrm{C}, 30 \mathrm{~min}$ for $94^{\circ} \mathrm{C} 12 \mathrm{~min}$ for 3 $\min$ for $60^{\circ} \mathrm{C}$, $¥$ for $4{ }^{\circ} \mathrm{C}$ (rest) and then $15 \mathrm{~min}$ for $37^{\circ} \mathrm{C}, 5 \min$ for $95^{\circ} \mathrm{C}, 4^{\circ} \mathrm{C}$ is set to $¥$. At the end of the cycles, the samples were diluted $1 / 5$ with nuclease-free water.

\section{Quantitative Reverse Transcriptase PCR (qRT-PCR)}

qRT-PCR were performed using a high-throughput Biomark Real-Time PCR system (Fluidigm, South San Francisco, CA). 4 ml pre-Mix (20X DNA Binding Dye Sample Loading Reagent) (Fluidigm, PN 100-3738), qPCR Master mix and Nuclease free water) were pipetted into 96-well wells. Pre-amplified samples were diluted 1/5. $2 \mathrm{ml}$ of these samples were pipetted into 96 well plate wells and a total of $6 \mathrm{ml}$ of sample mix was prepared. The prepared Assay mix (2X Assay Loading Reagent, 1X DNA Suspension Buffer and 100 $M$ forward and reverse primer) was pipetted as $3.5 \mathrm{ml}$ into the sample wells of the 96.96 Dynamic Array chip. 96.96. Dynamic Array Chip IFC loaded into controls. Then array chip was removed from the IFC controller and placed in the Fludigm Biomark. Thermal cycler protocol was set for $120 \mathrm{sec}$ for $50^{\circ} \mathrm{C}, 1800$ sec for $70{ }^{\circ} \mathrm{C}$ and $600 \mathrm{sec}$ for $25^{\circ} \mathrm{C}, 600 \mathrm{sec}$ for start-up temperature $600 \mathrm{sec}$ for $95^{\circ} \mathrm{C}$, and then $94{ }^{\circ} \mathrm{C}$ for $15 \mathrm{sec}$ (Denaturation), $30 \mathrm{sec}$ for $55^{\circ} \mathrm{C}$ (Binding), for $30 \mathrm{sec} 70^{\circ} \mathrm{C}$ (Elongation) and $30 \mathrm{cycles}$.

\section{Statistical Analysis}

Shaphiro wilk test was used to test the normal distribution of the numerical data in the patient and control groups. Student $t$ test was used to compare the variables with normal distribution in two groups and Mann Whitney $U$ test was used to compare the variables with normal distribution in two groups. In order to compare the measurements of miRNA expression levels before and after the operation in the patient group, repeated measures analysis of variance and LSD multiple comparison tests in normally distributed variables were used. Friedman 2-way analysis of variance and all pairwise multiple comparison tests were used for non-normally distributed variables. The relationship between the expression levels of microRNAs and cardiac markers was tested with spearman correlation coefficient. Analyzing real-time PCR data by the comparative DCT method [6]. Cut off values were determined as a result of ROC analysis for the variables of miRNA expression levels before the operation. SPSS 22.0 software (IBM SPSS Statistics for Windows, Version 22.0. Armonk, NY: IBM Corp.) was used in the analysis. $\mathrm{P}<0.05$ was considered significant.

\section{Results}

\section{Demographic and clinical findings of the patient and control group}

When the patient and control groups were compared in terms of demographic characteristics, significant differences were found between age, LDH, blood urea nitrogen (BUN) $(p<0.001)$ and glucose $(p<0.002)$ 
values. Cardiac troponin, creatinine phosphokinase (CPK) and creatinine kinase-MB (CK-MB) values of preoperative patient group and control group were compared and significant differences were found between CK-MB and cardiac troponin values $(p<0.001)$. Demographic and clinical findings of the patient and control groups are shown in Tables 1 and 2, the operation data of these groups are given in Table 3 .

Table 1

Demographic and clinical data of patient and control groups.

\begin{tabular}{|llll|}
\hline $\begin{array}{l}\text { Demographic and Clinical } \\
\text { Features }\end{array}$ & $\begin{array}{l}\text { Patient } \\
(\mathrm{M}=20, \mathrm{~F}=26) \\
\text { MEAN } \pm \text { STD }\end{array}$ & $\begin{array}{l}\text { Control } \\
(\mathrm{M}=16, \mathrm{~F}=\mathbf{3 2}) \\
\text { MEAN } \pm \text { STD }\end{array}$ & $P$ \\
\hline Age & $62.630 \pm 11.249$ & $42.340 \pm 11.249$ & $\begin{array}{l}\mathbf{0 . 0 0 1} \\
*\end{array}$ \\
\hline LDH & $228.159 \pm 65.975$ & $192.438 \pm 23.828$ & $\begin{array}{l}\mathbf{0 . 0 0 1} \\
*\end{array}$ \\
\hline BUN & $18.620 \pm 8.684$ & $13.790 \pm 9.908$ & $\begin{array}{l}0.001 \\
*\end{array}$ \\
\hline Glucose & $100.304 \pm 8.684$ & $94.708 \pm 9.908$ & $\begin{array}{l}\mathbf{0 . 0 0 2} \\
*\end{array}$ \\
\hline $\begin{array}{l}\text { LDH, Lactate Dehydrogenease; BUN, Blood Urea Nitrogen, M, Male; F, Female, P-values }<0.05 \text { are } \\
\text { indicated in bold }\end{array}$ & & \\
\hline
\end{tabular}

Table 2

Cardiac marker values of the patient and control groups before the operation.

\begin{tabular}{|llllll|}
\hline & Group & N & Mean & Std. Deviation & $P$ \\
\hline Troponin I & Control & 48 & 0.021 & 0.144 & $\mathbf{0 . 0 0 1}$ * \\
& Patient & 46 & 0.862 & 2.800 & \\
\hline CPK & Control & 48 & 79.125 & 40.256 & 0.812 \\
& Patient & 46 & 87.976 & 57.070 & $\mathbf{0 . 0 0 1}$ * \\
CK-MB & Control & 48 & 18.102 & 4.738 & \\
\hline & Patient & 46 & 27.902 & 17.597 & \\
\hline
\end{tabular}


Table 3

Operation data of patient group

\begin{tabular}{|ll|}
\hline Intensive care (hour) & $49.956 \pm 8.817$ \\
\hline Time Spent in the hospital after surgery (day) & $5.544 \pm 0.836$ \\
\hline Weight (kg) & $80.348 \pm 7.218$ \\
\hline Cardiopulmonary bypass time (minute) & $54.174 \pm 9.481$ \\
\hline Kross Clamp Time (minute) & $37.696 \pm 7.387$ \\
\hline Bypass number & $3.304 \pm 0.866$ \\
\hline
\end{tabular}

There was a significant decrease in the expression values of miR-21, miR-199a-5p, miR-199b-5p, miR$181 a$, miR-320a in the preoperative patient and control groups $(p<0.001)$. When miRNA changes were evaluated in the patient group before and after the operation, the significant differences were found only between the 1st and 24th hours for miR-199a-5p ( $p=0.044)$. Mean $\Delta C T$ and standard deviation values is shown in Table 4. ROC value belong to patients and controls are shown in Table 5. 
Table 4

Mean $\triangle C T$ and standard deviation values of patient and control groups.

\begin{tabular}{|c|c|c|c|c|c|}
\hline miRNA name & Groups & $\mathbf{N}$ & Mean $\Delta \mathrm{Ct}$ & Std. Deviation & $P$ \\
\hline \multirow[t]{4}{*}{ miR-21 } & Control & 48 & 2.393 & 1.353 & \multirow[t]{4}{*}{$0.001 *$} \\
\hline & Pre-Op & 46 & 3.732 & 2.389 & \\
\hline & Post-op 1 & 46 & 3.850 & 2.662 & \\
\hline & Post- op 24 & 46 & 3.860 & 2.272 & \\
\hline \multirow[t]{4}{*}{ miR-199a-5p } & Control & 48 & 7.639 & 2.499 & \multirow[t]{4}{*}{$0.001 *$} \\
\hline & Pre-Op & 46 & 10.994 & 3.725 & \\
\hline & Post-op 1 & 46 & 10.480 & 3.778 & \\
\hline & Post- op 24 & 46 & 11.727 & 3.424 & \\
\hline \multirow[t]{4}{*}{ miR-199b-5p } & Control & 48 & 8.246 & 1.570 & \multirow[t]{4}{*}{$0.001 *$} \\
\hline & Pre-Op & 46 & 10.560 & 3.496 & \\
\hline & Post-op 1 & 46 & 10.285 & 3.310 & \\
\hline & Post- op 24 & 46 & 10.810 & 3.170 & \\
\hline \multirow[t]{4}{*}{ miR-181a } & Control & 48 & 9.061 & 2.245 & \multirow[t]{4}{*}{$0.001 *$} \\
\hline & Pre-Op & 46 & 11.580 & 3.533 & \\
\hline & Post-op 1 & 46 & 10.390 & 3.580 & \\
\hline & Post- op 24 & 46 & 10.680 & 3.410 & \\
\hline \multirow[t]{4}{*}{ miR-320a } & Control & 48 & 2.016 & 1.587 & \multirow[t]{4}{*}{$0.001 *$} \\
\hline & Pre-Op & 46 & 3.555 & 3.113 & \\
\hline & Post-op 1 & 46 & 3.901 & 3.606 & \\
\hline & Post- op 24 & 46 & 3.618 & 3.190 & \\
\hline
\end{tabular}


Table 5

The Receiver Operating Characteristics Curve Analyses of the Five microRNA.

\begin{tabular}{|c|c|c|c|c|c|c|c|}
\hline $\begin{array}{l}\text { Compared } \\
\text { Groups }\end{array}$ & miRNAs & AUC & $95 \% \mathrm{Cl}$ & $\begin{array}{l}\text { P- } \\
\text { Value }\end{array}$ & $\begin{array}{l}\text { Specificity } \\
(\%)\end{array}$ & $\begin{array}{l}\text { Sensitivity } \\
\text { (\%) }\end{array}$ & Criterion \\
\hline $\begin{array}{l}\text { Coronary artery } \\
\text { patients }\end{array}$ & miR-21 & 0.777 & $\begin{array}{l}{[0.680-} \\
0.857]\end{array}$ & $\begin{array}{l}< \\
0.0001\end{array}$ & 0.875 & 0.652 & $>14.691$ \\
\hline \multirow{4}{*}{$\begin{array}{l}\text { vs } \\
\text { Control }\end{array}$} & $\begin{array}{l}\text { miR- } \\
199 a-5 p\end{array}$ & 0.810 & $\begin{array}{l}{[0.716-} \\
0.883]\end{array}$ & $\begin{array}{l}< \\
0.0001\end{array}$ & 0.687 & 0.869 & $>19.283$ \\
\hline & $\begin{array}{l}\text { miR- } \\
199 b-5 p\end{array}$ & 0.808 & $\begin{array}{l}{[0.714-} \\
0.882]\end{array}$ & $\begin{array}{l}< \\
0.0001\end{array}$ & 0.792 & 0.826 & $\begin{array}{l}> \\
20.301\end{array}$ \\
\hline & miR-181a & 0.784 & $\begin{array}{l}{[0.687-} \\
0.862]\end{array}$ & $\begin{array}{l}< \\
0.0001\end{array}$ & 0.854 & 0.630 & $\begin{array}{l}> \\
21.580\end{array}$ \\
\hline & miR-320a & 0.784 & $\begin{array}{l}{[0.688-} \\
0.863]\end{array}$ & $\begin{array}{l}< \\
0.0001\end{array}$ & 0.813 & 0.791 & 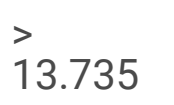 \\
\hline
\end{tabular}

\section{Correlation Between Cardiac Biomarkers And Mirnas}

We evaluated the relationship between changes in plasma markers of cardiac markers and miRNA expression. There was a positive weak correlation between miR-21 and cardiac troponin levels in the patient group $(r=0.344, p=0.019)$. However, no correlation was found between miR-21 and CK-MB values. There was a negatively weak correlation between miR-181a and cardiac troponin values measured at 1 hour and 24 hours $(r=-0.331, p=0.025,-r=0.361, p=0.014)$. There was a weak positive correlation between miR-181a values measured 1 hour postoperatively and CK-MB values measured before and 1 hour postoperatively $(r=0.306, p=0.039,-r=0.321, p=0.030)$. In the patient group, a moderate negative correlation was found between miR-199a-5p values measured 24 hours postoperatively and cardiac troponin values measured 1 hour postoperatively $(r=-0.469, p=0.001)$. There was no significant relationship between miR-199a and CK-MB values. There was no significant relationship between miR-199b and cardiac troponin and CK-MB levels before and after the operation. There was a weak positive correlation between miR-320a and cardiac troponin levels in the patient group $(r=0.318, p=0.031)$. However, no significant relationship was found between miR-320a and CK-MB values.

\section{Discussion}

Coronary artery disease is the most common cardiovascular disease. Studies on the positive and negative effects of miRNAs on the pathogenesis of the disease show that circulating miRNAs can be used as biomarkers in the diagnosis of coronary artery disease. Therefore, in our study, the role of 
miRNAs in the diagnosis of coronary artery disease and its relationship with the parameters in the clinical evaluation process were investigated.

miRNAs have gene regulatory effects [7]. In studies conducted in patients with myocardial infarction, serum levels of miR-1 and miR-133a are high [8, 9]. Heart-related studies of microRNAs have mostly focused on their effects on cardiac remodeling processes. It has been shown that miRNAs have significant potential in evaluating the early and late stages (early detection of a heart attack) of cardiac damage, regeneration, rhythm regulation, cardiac growth, and myocardial infarction [10-12]. miR-1, miR133 and miR-208 have also been shown to be effective in many heart related conditions. These have been identified as "cardio-specific miRNAs" $[5,13,14]$. Therefore, we investigated human plasma samples that have not previously been studied in the presence of clinical data. We evaluated miRNA levels under ischemic conditions and obtained data that these miRNAs can be evaluated as markers in ischemic conditions in patients with coronary artery disease.

miR-21 is one of the miRNAs considered to be oncogenic due to its proliferative and anti-apoptotic effect in cancer cells $[15,16]$. MiR-21 inhibition in cultured cardio myocytes was found to have a negative effect on cardio myocyte hypertrophy [17]. When MiR-21 is inhibited by antagomir approach, cardiac hypertrophy and fibrosis are reduced [18], as well as protective effects against heart damage caused by I/R [19]. This effect, which was initially useful in preventing cardiac damage, becomes harmful when the effects that lead to damage persist or recur. MiR-21 levels are high in unbalanced angina patients [20] and atherosclerosis model mice [21]. Patients with heart failure have high levels of miR-21, brain natriuretic peptide and miR-21 in serum samples collected from both the peripheral vein and coronary sinus [22]. In patients suffering from acute myocardial infarction, there is a strong correlation between miR-21 and cardiac markers such as cardiac troponin, CK and CK-MB [23].

In our study, a positive weak correlation was found between preoperative miR-21-5p and cardiac troponin values in the patient group. While there was no correlation between cardiac troponin and miR-21-5p values measured at postoperative hour 1 , there was a negative and weak correlation between cardiac troponin measured at 1 hour and miR-21-5p measured at 24 hours. However, no correlation was found between CK-MB and miR-21-5p values at the 1st and 24th hours. Our patient group was not acute and was selected from individuals with a history of myocardial infarction. Therefore, we think that the miR-21 levels were lower in patients with coronary artery disease $(p<0.001)$. In addition, there was no significant difference between preoperative and postoperative miR-21-5p levels in patients with coronary artery disease $(p<0.05)$. These results were found to be different according to the literature data that miR-21 levels were higher in patients with coronary artery disease and heart failure compared [19-23]. This difference may be thought to occur because miR-21-5p levels correlate with cardiac markers. The diagnostic value of miR-21 in the patient group in our study could be considered as moderate. From this point of view, our results are consistent with the literature [24] and the nomination of miR-21 for diagnosis can be confirmed by repeated studies. 
miR-199a-5p is localized in the introns of the dynamin genes and is expressed in cancer, brain, liver and cardiovascular system, particularly in cardio myocytes and endothelial cells $[25,26]$. It is also associated with cancer and cardiovascular diseases $[27,28]$. miR-199a-5p decreased in cardio myocytes exposed to hypoxia [27, 29[. High levels of miR-199a in circulating micro vesicles are associated with a reduced risk of cardiovascular events in patients with stable coronary artery disease [30]. In our study, miR-199a-5p levels were lower in patients with coronary artery disease than in the control group $(p<0.001)$. When miR$199 a-5 p$ changes were evaluated in the patient group before and after the operation, significant differences were found between the 1 st and 24 th hours $(p<0.044)$. The increase in the level of miR-199a 1 hour after the operation may be due to the saturation of the Hif-1alfa in the medium to achieve saturation and then to decrease its levels. MiR-199a-5p values measured in the patient group at 24th postoperative hour and cardiac troponin levels measured at 1 hour postoperatively were negatively moderately correlated. There was no significant relationship between miR-199a-5p and CK-MB values ( $p$ $>0.005$ ). When we evaluate the obtained data, we think that changes in miR-199a-5p levels may be an important biomarker for coronary artery disease.

One of the miRNAs involved in cardiac hypertrophy is miR-199b-5p and plays an important role in the development of various organs such as the heart [31,32]. miR-199b has been shown to activate the calcineurin/NFAT signaling pathway by targeting double-specific tyrosine phosphorylation-regulating kinase 1A [31] and improving heart function when miR-199b is inhibited [33]. It has been reported that miR-199b-5p regulates the nuclear factor kappa-B (NF-KB) signal pathway in the inflammatory response of the nervous system and suppresses neurodegenerative disease [34]. In another study, monocytes treated with lipopolysaccharide have been shown to have a significant decrease in miR-199b-5p levels and an increase in GSK3 $\beta$ expression and anti-inflammatory effect by activation of the NF-KB pathway [14]. In our study, miR-199b-5p levels were lower in patients with coronary artery disease compared to the control group $(p<0.001)$. Low miR-199b-5p levels result in the inability to inhibit NFk-B protein and inflammation. Therefore, it can be said that it contributes to the etiopathogenesis of coronary artery disease. However, there was no significant difference between miR-199b-5p levels before and after surgery in patients with coronary artery disease $(p>0.05)$. There was no significant relationship between miR-199b-5p and cardiac troponin and CK-MB values for before and after operation in the patient group. According to ROC data, miR-199b-5p levels can be an important marker for coronary artery disease. We have seen in the literature that miR-199b-5p levels have not been studied in patients with coronary artery disease. To the best of our knowledge, this is the first study to investigate the correlation of miR-199b-5p levels with cardiac markers before and after bypass grafting in patients with coronary artery disease. Further studies are needed to evaluate miR-199b-5p levels in patients with coronary artery disease and to support our results.

miR-320a has been mostly studied in cancer and heart disease and also varies in heart disease, but has been studied in a limited number of patient groups $[35,36]$. It suppresses cardio myocyte apoptosis of downregulation of miR-320a and protects against myocardial ischemia and reperfusion injury by targeting insulin-like growth factor 1 (IGF-1) [37]. In another study, it has been shown that downregulation of miR-320a suppresses cardio myocyte apoptosis and protects against myocardial ischemia and 
reperfusion damage by targeting insulin-like growth factor 1 (IGF-1) [38]. miR-320a is down-regulated in patients with myasthenia gravis [39]. In these patients, the expression of cyclooxygenase-2 (COX-2) is high, and over-expression of pro-inflammatory cytokines has been observed [40]. In our study, miR-320a levels were lower in patients with coronary artery disease compared to the control group $(p<0.004)$. There was no significant difference between the preoperative and postoperative miR-320a levels in patients ( $p>$ 0.05). There was a weak positive correlation between preoperative miR-320a levels and cardiac troponin levels in patients and there was no significant relationship between miR-320a and CK-MB. The first ROC analysis for miR-320a in patients with coronary artery disease was conducted in this study, and we believe it can be used to diagnose the disease, according to our data.

MiR-181a is highly expressed in the mammalian brain [41]. It plays an important role in various biological events, such as immune modulation and inflammation [42]. Inhibition of miR-181a has been found to increase neuronal loss due to ischemia and bcl-2 levels, which are anti-apoptotic protein [43] and upregulated in atherosclerotic vessels compared to normal vessels [44]. In the neurogenic hypertension model, miR-181a levels were low and renin mRNA levels were high [45]. In a study of unstable angina and acute myocardial infarction in circulation, MiR-181a levels were higher in the myocardial infarction group [14]. In our study, miR-181a levels were lower than the control group $(p<0.001)$. There was no change in miR-181a levels according to preoperative values after reperfusion with bypass graft $(p>0.05)$. There was a negative weak correlation between miR-181a-5p and cardiac troponin values after surgery in patients with coronary artery disease and weakly positive. There was a correlation between postoperative miR-181a-5p and CK-MB. The role of MiR-181a in cardiovascular diseases has not been described. As a result, miR-181a-5p has diagnostic potential in coronary artery disease. Therefore, we think that it can be considered as a biomarker for this disease if it is supported by new studies.

\section{Conclusions}

In our study, the expression levels of miR-21-5b, miR-199a-5p, miR-199b, miR-181a and miR-320a were lower in patients with coronary artery disease than in the control group. Moreover, miR-199a-5p was higher in patients with coronary artery disease than in the first hour and 24th hour after the operation. Accordingly, it can be said that decreased levels of these miRNAs may pave the way for the pathogenesis of coronary artery disease. miR-199a can be used to predict future adverse events in coronary artery bypass graft surgery patients, optimize patient care, and improve the patient clinic. Clinicians need to know the morbidity and mortality of patients, and miR-199a-5p has the potential to respond to this need as an epigenetic marker.

\section{Limitations}

This is a case-control study with a relatively small sample size. MiRNAs' extracellular assets, molecular processes, oscillations, transports, molecules and mechanisms mediating these processes have not been fully elucidated. Techniques and skills are required to detect circulating miRNAs and use them in routine 
laboratories. In addition, miRNAs are found in the entire circulation and more research is needed for tissue expression.

\section{Abbreviations}

CVD

Cardiovascular disease

TEKHARF

Prevalence of heart disease and risk factors in Turkish adults

miRNAs

microRNAs

I/R

Ischemia/reperfusion

LDH

Lactate dehydrogenase

BUN

Blood urea nitrogen

CK

Creatinine kinase

CK-MB

Creatinine kinase myocardial band

CPK

Creatinine phosphokinase

ROC

Receiver operating characteristic

AUC

Area under the ROC curve

NFAT

Nuclear factor of activated T-cells

NF-KB

Nuclear factor kappa B

GSK3 $\beta$

Glycogen synthase kinase $3 \beta$

IGF-1

Insuline growth factor 1

COX-2

Cyclooxygenase-2

\section{Declerations}




\section{Ethics approval and consent to participate}

Gaziantep University Faculty of Medicine Ethics Committee approved the working procedure. All sampling was carried out in accordance with the 2013 Helsinki declaration guidelines and ethical rules.

\section{Consent for publication}

The manuscript is approved by all authors for publication.

\section{Availability of data and materials}

The datasets supporting the conclusions of this article are included within the article.

\section{Competing interests}

The authors declare that they have no competing interests.

\section{Funding}

This study was approved by Gaziantep University Medical School Medical Ethics Committee with the decision numbered 2016/276 and supported by Gaziantep University Scientific Research Projects Unit (TF.DT.17.11).

\section{Authors' contributions}

EK, ŞGY, MY, NB, and MN designed the research. EK, and ŞGY performed the experiments. MY and NB provided the resources. EK and ŞGY wrote the original draft. EK, ŞGY, MY, NB, and MN review and editing the paper. All authors read and approved the final manuscript.

\section{Acknowledgments}

We sincerely thank the Gaziantep University Research Projects Unit for their support.

\section{Author informations}

\section{Erman Kandilli, PhD}

Doctorate graduate from Medical Pharmacology

From Gaziantep University and Pharmacist,

Gaziantep, Turkey

Phone: +90-506-650 4664

Fax: +90-342-360 1617 
Email: ermankandilli@gmail.com

ORCID ID: 0000-0001-9979-8152

\section{Murat Yardımcı, PhD}

Assistant Professor

Department of Cardiology

SANKO University, Gaziantep, Turkey

Phone : +90-342-211 6500

Fax : +90-342-211 6500

E-mail : muratyardimci@hotmail.com

ORCID ID: 0000-0001-7062-6015

\section{Necla Benlier, PhD}

Assistant Professor

Department of Medical Pharmacology

SANKO University, Gaziantep, Turkey

Phone : +90-342-211 6500

Fax : $+90-342-2116500$

E-mail : nbenlier@sanko.edu.tr

ORCID ID: 0000-0002-8008-0658

\section{Muradiye Nacak, PhD}

Professor

Department of Medical Pharmacology

Gaziantep University, Gaziantep, Turkey

Phone : +90-342-211 6500

Fax : $+90-342-2116500$ 
E-mail : mnacak2000@yahoo.com

ORCID ID: 0000-0002-2651-4021

\section{References}

1. World Health Organization (WHO). About cardiovascular diseases. Online Referencing. [cited 2019 Nov 13]. Retrieved from: http://www.who.int/cardiovascular_diseases/about_cvd/en/.

2. World Health Organization (WHO). World Heart Day. Online Referencing. [cited 2019 Nov 13]. Retrieved from: http://www.who.int/cardiovascular_diseases/en/.

3. Onat A, Can G. Erişkinlerimizde kalp hastalıkları prevalansı, yeni koroner olaylar ve kalpten ölüm sıklığı. Tıp Dünyasının Kronik Hastalıklara Yaklaşımına Öncülük, İstanbul: Logos Yayıncılık. 2017:21-28.

4. Kathiriya IS, Nora EP, Bruneau BG. Investigating the transcriptional control of cardiovascular development. Circ Res. 2015;116(4):700-14.

5. Chistiakov DA, Orekhov AN, Bobryshev YV. Cardiac-specific miRNA in cardiogenesis, heart function, and cardiac pathology (with focus on myocardial infarction). J Mol Cell Cardiol. 2016;94:107-21.

6. Schmittgen TD, Livak KJ. Analyzing real-time PCR data by the comparative CT method. Nat Protoc. 2008;3:1101-8.

7. Vidigal JA, Ventura A. The biological functions of miRNA's: lessons from in vivo studies. Trends Cell Biol. 2015;25(3):137-47.

8. Ai J, Zhang R, Li Y, Pu J, Jiao J, Li K, et al. Circulating microRNA-1 as a potential novel biomarker for acute myocardial infarction. Biochem Biophys Res Commun. 2010;391(1):73-7.

9. Wang GK, Zhu JQ, Zhang JT, Li Q, He J, Qin YW, Jing Q. Circulating microRNA: a novel potential biomarker for early diagnosis of acute myocardial infarction in humans. Eur Heart J. 2010;31(6):659-66.

10. Tian J, An XJ, Niu L. Role of microRNAs in cardiac development and disease. Exp Ther Med. 2017;13(1)1):3-8.

11. Bialek S, Gorko D, Zajkowska A, Koltowski Ł, Grabowski M, Stachurska A, et al. Release kinetics of circulating miRNA-208a in the early phase of myocardial infarction. Kardiol Pol. 2015;73(8):613-9.

12. Ling TY, Wang XL, Chai Q, LuT, Stulak JM, Joyce LD, et al. Regulation of cardiac CACNB2 by microRNA-499: Potential role in atrial fibrillation. Bba Clin. 2017;7:78-84.

13. Fan ZX, Yang J. The role of microRNAs in regulating myocardial ischemia reperfusion injury. Saudi Med J. 2015;36(7):787-93.

14. Zhu J, Yao K, Wang Q, Guo J, Shi H, Ma L, et al. Circulating miR-181a as a potential novel biomarker for diagnosis of acute myocardial infarction. Cell Physiol Biochem. 2016;40(6):1591-602.

15. Gu JB, Bao XB, Ma Z. Effects of miR-21 on proliferation and apoptosis in human gastric adenocarcinoma cells. Oncol Lett. 2018;15(1):618-22. 
16. Feng YH, Tsao CJ. Emerging role of microRNA-21 in cancer. Biomed Rep. 2016;5(4):395-402.

17. Wehbe N, Nasser SA, Pintus G, Badran A, Eid AH, Baydoun E. MicroRNAs in Cardiac Hypertrophy. Int J Mol Sci. 2019;20(19):4714.

18. Wang J, Liew OW, Richards AM, Chen YT. Overview of MicroRNAs in Cardiac Hypertrophy, Fibrosis, and Apoptosis. Int J Mol Sci. 2016;17(5):749.

19. Xu X, Lu Z, lin V, May A, Shaw DH, Wang Z. MicroRNA miR-24-3p Reduces Apoptosis and Regulates Keap1-Nrf2 Pathway in Mouse Cardiomyocytes Responding to Ischemia/Reperfusion Injury. Oxidative Medicine cellular longevity. 2018;2018:1-9.

20. Ren J, Zhang J, Xu N, Han G, Geng Q, Song J, et al. Signature of circulating microRNAs as potential biomarkers in vulnerable coronary artery disease. Plos One. 2013;8(12):e80738.

21. Han H, Qu G, Han C, Wang Y, Sun T, Li F, et al. MiR-34a, miR-21 and miR-23a as potential biomarkers for coronary artery disease: a pilot microarray study and confirmation in a 32 patient cohort. Exp Mol Med. 2015;47:e138.

22. Zhang JH, Xing Q, Zhou XH, Li J, Zhang L, Zhou Q, Tang B. Circulating miRNA-21 is a promising biomarker for heart failure. Mol Med Rep. 2017;1(5):7766-74.

23. Zhang Y, Liu YJ, Liu T, Zhang H, Yang SJ. Plasma microRNA-21 is a potential diagnostic biomarker of acute myocardial infarction. Eur Rev Med Pharmaco. 2016;20(2):323-9.

24. Liu J, Li SF, Lee CY, Song JX, Zhang F, Cui YX, Chen H. Circulating microRNAs as potential biomarkers for unstable angina. Int J Clin Exp Patho. 2017;10(8):9073-83.

25. Aranda JF, Canfran-Duque A, Goedeke L, Suarez, Fernandez-Hernando C. The miR-199-dynamin regulatory axis controls receptor-mediated endocytosis. J Cell Sci. 2015;128(17):3197-209.

26. Le NT, Abe JI. MicroRNA 199a and the eNOS (Endothelial NO Synthase)/NO Pathway. Artherioscler Thromb Vas Biol. 2018;38:2278-80.

27. Chen C, Ponnusamy M, Liu C, Gao J, Wang K, Li P. MicroRNA as a Therapeutic Target in Cardiac Remodeling. BioMed Res Int. 2017;2017:1-25.

28. Lynch SM, Ward M, McNulty H, Angel CZ, Horigan G, Strain JJ. Serum levels of miR-199a-5p correlates with blood pressure in premature cardiovascular disease patients homozygous for the MTHFR 677C > T polymorphism. Genomics. 2020;112(1):669-76.

29. Liu DW, Zhang YN, Hu HJ, Zhang PQ, Cui W. Downregulation of microRNA-199a-5p attenuates hypoxia/reoxygenation-induced cytotoxicity in cardiomyocytes by targeting the HIF-1a-GSK3 $\beta$-mPTP axis. Mol Med Rep. 2019;19(6):5335-44.

30. Jansen F, Yang XY, Proebsting S, Hoelscher M, Przybilla D, Baumann K, et al. MicroRNA expression in circulating microvesicles predicts cardiovascular events inpPatients with coronary artery disease. J Am Heart Assoc. 2014;3(6):e001249.

31. Martins PA, Salic K, Gladka MM, Armand AS, Leptidis S, el Azzouzi H, et al. MicroRNA-199b targets the nuclear kinase Dyrk1a in an auto-amplification loop promoting calcineurin/NFAT signalling. Nat Cell Biol. 2010;12(12):1220-7. 
32. Schulz RA, Yutzey KE. Calcineurin signaling and NFAT activation in cardiovascular and skeletal muscle development. Dev Biol. 2004;266(1):1-16.

33. Kuhn C, Frank D, Will R, Jaschinski C, Frauen R, Katus HA, Frey N. DYRK1A is a novel negative regulator of cardiomyocyte hypertrophy. J Biol Chem. 2009;284(25):17320-7.

34. Duygu B, Poels EM, Juni R, Bitsch N, Ottaviani L, Olieslagers S, et al. miR-199b-5p is a regulator of left ventricular remodeling following myocardial infarction. Non-coding RNA Research. 2017;2:1826.

35. Devaux Y, Mueller M, Haaf P, Goretti E, Twerenbold R, Zangrando J, et al. Diagnostic and prognostic value of circulating microRNAs in patients with acute chest pain. J Intern Med. 2015;277(2):260-71.

36. Jantti TAJ, Segersvard H, Lassus JP, Devaux Y, Vausort M, Immonen K, et al. Circulating microRNAs miR-21, miR-122a, miR-320a and miR-423 predict mortality in patients with cardiogenic shock. Eur Heart J. 2016;37 Suppl:321.

37. Chen C, Wang Y, Yang S, Li H, Zhao G, Wang F, et al. MiR-320a contributes to atherogenesis by augmenting multiple risk factors and down-regulating SRF. J Cell Mol Med. 2015;19(5):970-85.

38. Song CL, Liu B, Diao HY, Shi YF, Zhang JC, Li YX, et al. Down-regulation of microRNA-320 suppresses cardiomyocyte apoptosis and protects against myocardial ischemia and reperfusion injury by targeting IGF-1. Oncotarget. 2016;7(26):39740-57.

39. Ni CW, Qiu HW, Jo H. MicroRNA-663 upregulated by oscillatory shear stress plays a role in inflammatory response of endothelial cells. Am J Physiol Heart Circ Physiol. 2011;300(5):H1762-9.

40. Cheng ZA, Qiu SB, Jiang L, Zhang A, Bao W, Liu P, Liu J. MiR-320a is downregulated in patients with myasthenia gravis and modulates inflammatory cytokines production by targeting mitogen-activated protein kinase 1. J Clin Immunol. 2013;33(3):567-76.

41. Miska EA, Alvarez-Saavedra E, Townsend M, Yoshii A, Sestan N, Rakic P, et al. Microarray analysis of microRNA expression in the developing mammalian brain. Genome Biol. 2004;5(9):R68.

42. Sun $\mathrm{XH}$, Sit A, Feinberg MW. Role of miR-181 family in regulating vascular inflammation and immunity. Trends Cardiovas Med. 2014;24(3):105-12.

43. Moon JM, Xu LJ, Giffard RG. Inhibition of microRNA-181 reduces forebrain ischemia-induced neuronal loss. J Cerebr Blood F Met. 2013;33(12):1976-82.

44. Liu G, Li Y, Gao XG. microRNA-181a is upregulated in human atherosclerosis plaques and involves in the oxidative stress-induced endothelial cell dysfunction through direct targeting Bcl-2. Eur Rev Med Pharmaco. 2016;20(14):3092-100.

45. Jackson KL, Marques FZ, Watson AMD, Palma-Rigo K, Nguyen-Huu TP, Morris BJ, et al. A novel interaction between sympathetic overactivity and aberrant regulation of renin by miR-181a in BPH/2J genetically hypertensive mice. Hypertension. 2013;62(4):775-81. 